\title{
A comparative analysis of reading strategies across ESP students of humanities and engineering
}

\author{
Vaez Dalili, Mehdi $₫$ \\ University of Isfahan, Iran (vaez.dalili@fgn.ui.ac.ir) \\ Tavakoli, Mansoor \\ University of Isfahan, Iran (mr.tavakoli14@gmail.com)
}

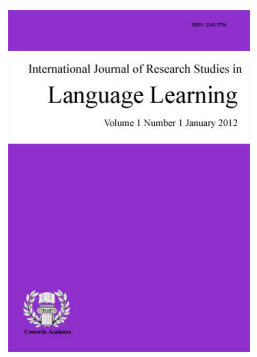

ISSN: $2243-7754$ Online ISSN: 2243-7762

OPEN ACCESS

\section{Abstract}

This study set out to explore whether significant differences existed between two groups of EFL students of different fields of study (i.e. humanities and engineering) in terms of their metacognitive awareness and use of certain reading strategies while reading English for Specific Purposes (ESP) texts. Seventy lower-intermediate college-level students (35 engineering students and 35 students of humanities) completed the Metacognitive Awareness of Reading Strategies Inventory (Mokhtari \& Reichard, 2002) to measure their metacognitive awareness of ESP reading strategies. The inventory includes 3 strategy subscales with 30 items: Global Reading Strategies (GLOB), Problem-Solving Strategies (PROB), and Support Reading Strategies (SUP). A series of t-tests were conducted to figure out the differences between the two groups of students in connection with each of the strategies in the MARSI inventory. The results showed that in spite of the fact that the two groups were studying different fields of study, they reported strikingly similar patterns of reading strategy awareness and confirmed having used almost all of the strategies while reading ESP materials. However, the engineering students reported using some types of reading strategies more frequently than did the humanities students. The findings of the study will not only explain the differences and similarities between engineering and humanities students, but also help to challenge the purely speculative assumption as to the deficiencies in strategy-based ESP reading comprehension of humanities students.

Keywords: reading strategies; metacognition; ESP reading; Metacognitive Awareness of Reading Strategies Inventory (MARSI) 


\section{A comparative analysis of reading strategies across ESP students of humanities and engineering}

\section{Introduction}

For most EFL/ESL students, reading is the most important part of their English course, the aims of which are to consolidate grammar (at elementary level), expand vocabulary and develop effective reading strategies. Recently, with the explosion of research in EFL/ESL reading, reading strategies employed in reading comprehension have been investigated widely, and implemented into teaching (Færch \& Kasper, 1983; Wenden \& Rubin, 1987; O’Malley \& Chamot, 1990; Oxford, 1990).

Studies concerning reading strategies have mainly been concerned with two categories of reading strategies: cognitive and metacognitive. Cognitive strategies assist L2 readers in constructing meaning from the text. Metacognitive strategies are the ones which function to regulate or monitor cognitive strategies (Devine, 1993; Flavell, 1981). They include evaluating the possible outcome of a problem-solving attempt, planning next moves, measuring the effectiveness of an attempted action, testing, modifying, and assessing one's strategies for learning (Baker \& Brown, 1984). Whereas skimming a text for the main textual information is regarded as a cognitive strategy, evaluation of the effectiveness of skimming for gathering the main information would be considered a metacognitive strategy (Devine, 1993).

Research addressing metacognitive reading strategies by L2 readers of English has shown that "awareness and monitoring of one's comprehension processes are critically important aspects of skilled reading" (Mokhtari \& Reichard, 2002, p. 249). Such awareness and monitoring processes are known as metacognition, which can be taken as the knowledge of readers' cognition about their own reading and the checking procedures they utilise while monitoring and manipulating the comprehension of a reading passage.

Previous studies on reader's metacognitive reading strategies have examined the effect of such factors as beliefs, L1 background, culture-specific instruction, and L2 proficiency. However, in spite of the expanding bulk of research on different aspects of the issue, virtually no in-depth research currently exists which examines the metacognitive awareness and the reading strategies used by ESP students majoring in different fields of study, and this is where the present study enters the picture to fill the lacunae.

The motivation behind the study derives from the common misconception among EFL practitioners in Iran that students of humanities, in comparison with engineering students, have always been regarded as less skilled learners in learning a second language, and especially in reading ESP courses. Based on this, the present study is intended to compare the metacognitive awareness of the reading strategies of ESP college students studying in engineering with those of humanities students. The means used to tap the metacognitive awareness of these two student groups was Mokhtari and Reichard's (2002) Metacognitive Awareness of Reading Strategies Inventory (Appendix A) which measures Global Reading Strategies (GLOB), Problem-Solving Strategies (PROB), and Support Reading Strategies (SUP).

The underlying hypothesis in undertaking this comparative study was that although both humanities and engineering students could be considered to have the requisite language proficiency for college-level ESP reading in English, they are unlikely to have similar strategic awareness in handling their ESP reading tasks because of the differences in their academic fields. To explore the hypothesis, the study was conducted to the find an answer to the following research question: Are there significant differences between engineering and humanities students in their metacognitive awareness and use of certain reading strategies while reading ESP materials? The rationale behind undertaking this cross-disciplinary study is that the reading potential of humanities students is usually underestimated and unjustly perceived as a problem among Iranian EFL 
A comparative analysis of reading strategies across ESP students of humanities and engineering

practitioners, and that careful study of the metacognitive knowledge and reading strategies used by this group of L2 readers indicates that all second language learners - including those stereotypically considered as disadvantaged - can uniformly employ strategic reading.

\section{Background of the study}

A number of studies have attempted to conceptualise the notion of strategies used by ESL/EFL learners, but no categorisation has been more successful than the one proposed by Oxford (1990). She offers a useful and comprehensive classification of the various strategies used by L2 learners, which falls into six strategies:

$>$ Cognitive strategies which learners use to manipulate or transform the language. Some examples of these strategies are predicting, summarizing, paraphrasing, note taking and using context clues;

$>$ Memory strategies are those strategies learners use to remember and retrieve some pieces of information. Such strategies include creating mental images through sorting words and associating concepts, semantic mapping, using mnemonic devices, using keywords, and employing new words in a context;

$>\quad$ Compensation strategies pertain to skills such as guessing, inference, or using reference materials (e.g. dictionaries, encyclopedias, etc.);

$>\quad$ Affective strategies are the strategies used by learners to encourage themselves so that they could lower their anxiety and improve their learning;

$>\quad$ Social strategies refer to strategies which learners use to involve other people in the learning process and cooperate with their peers. Typical examples of these strategies are questioning, request for correction, clarification requests, and feedback; and finally

$>\quad$ Metacognitive strategies are those used by learners to plan, regulate, monitor, and evaluate their own learning. Common examples of these strategies are setting goals and objectives, directed attention, self-monitoring, hypothesis testing, self-evaluation, correction of errors, etc.

Researchers investigating the area of L2 reading comprehension have long recognised the importance of metacognitive strategies because they distinguish between skilled and unskilled readers. Drawing on the concept of metacognitive strategies, Paris and Jacobs (1984) point out the differences between good and poor readers:

Skilled readers often engage in deliberate activities that require playful thinking, flexible strategies, and periodic self-monitoring. They think about the topic, look forward and backward in the passage, and check their own understanding as they read. Beginning readers or poor readers do not recruit and use these skills. Indeed, novice readers often seem oblivious to these strategies and the need to use them. (Paris \& Jacobs, 1984, p. 2083)

In general, more proficient readers exhibit certain types of reading behaviours. Table 1 in the following gives a list of key metacognitive reading strategies. The list provides a clear description of the characteristics of proficient readers and continues to develop as more and more research into the use of metacognitive strategies is undertaken.

Two dimensions of metacognitive ability have been distinguished: 1) knowledge of cognition or metacognitive awareness (i.e. declarative knowledge); and 2) actual use of metacognitive reading strategies (i.e. procedural knowledge). What matters is the combination of the two dimensions, which distinguishes the skilled from unskilled readers. Simply put, if readers have the knowledge of what is required to perform skillfully in a reading situation, then it is likely to take action to tackle a reading situation more efficiently. If, however, the readers don't know their own weaknesses as readers or the difficulties of the task at hand, then they can hardly take any steps to predict or manipulate the complexities of the reading task. 


\section{Table 1}

Key metacognitive reading strategies

\begin{tabular}{l} 
Purpose-oriented strategies \\
\hline Planning what to do next, steps to take \\
Reminding oneself about the purpose for reading \\
Evaluating information in terms of whether it leads to one's purpose \\
Deciding whether a text is relevant to one's purpose \\
Comparing information from one text with that of another \\
Reflecting on how well objectives were met \\
Evaluating the quality of a text \\
Checking the time one has available \\
\hline \multicolumn{1}{c}{ Comprehension-monitoring strategies } \\
\hline - Assessing comprehension \\
Evaluating one's understanding \\
Identifying difficulties in understanding \\
Summarizing what one has read \\
Restating for oneself what one has read \\
Reviewing a text after reading is completed \\
- Repair strategies \\
Re-reading \\
Slowing down and reading again \\
Trying to pronounce words \\
\hline Reflecting on what has been learned from the text \\
Underlining or marking in text \\
Thinking how to use a text in the future \\
Making notes about what one has read \\
Paraphrasing what the author said in order to remember it \\
\hline Note. Adapted from Grabe \& Stoller, 2002; Oxford, 1990; Sarig, 1993; Pressley, 2000; Anderson, 1991, 1999
\end{tabular}

The plethora of studies on the use of metacognitive strategies in $\mathrm{L} 2$ reading recognizes the significant role of these strategies in reading comprehension. In an earlier research project, Carrell (1984) discovered that explicit teaching of the rhetorical structure of reading passages helped students to have better performance in their reading comprehension. The participants of the study were 25 high-intermediate students of English as a second language (ESL), who were divided into an experimental and a control group. The experimental group was exposed to four discourse types (i.e. causation, comparison, description, and problem/solution) during five one-hour training sessions. The objective of the study was to see which group remembered more idea units (i.e. a single clause including main, dependent, and relative clauses). The study's results revealed that the students in the experimental group recalled a larger number of idea units in comparison with the students in the control group.

Devine (1988) conducted a study to compare the reading strategies employed by two low-intermediate L2 readers who were similar in their language proficiency but different in their reading assumptions. One of the two ESL readers, Stanislav, who held a PhD, was classified as a more skilled L1 reader but he was a form-centered L2 reader. In other words, he didn't comprehend much of L2 readings because he couldn't transfer his L1 higher-level reading strategies when reading L2 texts. In contrast, the second ESL reader, Isabella, who was a high-school graduate, was identified as a less skilled L1 reader but she was a meaning-centered L2 reader. Isabella proved to be a more capable L2 reader, understanding much of the texts she read through applying her L1 reading strategies to L2 reading situations. Despite having similar language proficiency and being different in their L1 reading skills, the readers seemed to perform differently in reading L2 texts. The difference could be explained by the differences in their metacognitive reading strategies found through an oral interview about their viewpoints on L2 reading. Although Stanislav was a better L1 reader, Isabella could outperform him because she was a meaning-centered reader who could transfer her top-down reading skills when reading L2 texts. Based on this study, it can be concluded that L2 readers' metacognitive awareness and their theoretical orientation toward 
A comparative analysis of reading strategies across ESP students of humanities and engineering

L2 reading affect their L2 reading skills more than their L1 reading ability or their language proficiency.

Barnett (1988) examined the relationship between actual and perceived use of reading strategies and how they affect reading comprehension. The participants of her study were 278 English students learning L2 French. In the first stage of the study, the students were asked to complete a background knowledge questionnaire before reading the French passages. In the second stage of the study, they were required to read an unfamiliar French reading passage and write a recall composition in English. In the third stage of the study, the students were asked to read another unfamiliar passage and take a sixteen-item multiple-choice test where they chose the best phrase, sentence or paragraph to continue the ending of the reading passage. In the final stage of the study, the students completed a seventeen-item English questionnaire on the types of perceived reading strategies they employed while reading the two passages. The results of the study revealed that there was a positive correlation between the reading comprehension level of the participants and their perceived use of reading strategies. Also, the students' use of actual strategy use was highly associated with their perceived strategy use. In other words, students who claimed to employ effective L2 reading strategies had better context-based understanding of the sentences, and also they seemed to perform better in their reading comprehension than those who did not think they used reading strategies.

Carrell (1989) explored the relationship between L2 readers' perceived use of reading strategies and their reading comprehension in both L1 and L2. Two groups of students with different language backgrounds participated in her study. The first group of participants was 45 intermediate and high-intermediate Spanish speakers studying English as second language. The second group consisted of 75 native speakers of English learning Spanish as foreign language. The participants read two reading passages in the language in question and then took a 10-item multiple-choice reading comprehension. The test was followed by metacognitive questionnaire, with each item eliciting the participants' agreement or disagreement on a 5-point scale. The questionnaire consisted of four different categories of metacognitive strategies: (1) repair strategies, (2) effective reading strategies, (3) confidence, and (4) reading difficulties. The results showed that in L1 reading, top-down strategies have no significant bearing on reading comprehension, and local or bottom-up strategies have negative correlation with reading comprehension. However, in L2 reading, global or top-down strategies had positive correlation with L2 reading comprehension, and the use of local or bottom-up strategies showed negative correlation with reading ability. Whereas for the skilled L2 English readers the use of global/top-down strategies were found to be more effective and efficient, for the less skilled L2 Spanish readers, the use of local/bottom-up strategies proved to be problematic and led to reading comprehension difficulties.

Bringing the findings of previous research on reading strategies directly into the classroom, Auerbach and Paxton (1997) asserted that teaching reading strategies can help L2 readers to become more skilled readers. In their study, they taught 20 college-level ESL students to take responsibility for the investigation of their own use of reading strategies. The students were required to explore their own reading strategies, keep reading journals, reflect on the differences between their existing and new reading strategies, and also apply their own findings to improve their concept, strategies and awareness of L2 reading comprehension. Through the course of the study, the increase in the metacognitive awareness of the students brought about dramatic changes in their reading behavior so that the L2 readers, who were initially obsessed with looking up every new vocabulary item in the dictionary, were now skilled enough to draw on the reading strategies they had explored and developed during the course of the study. Auerbach and Paxton's research revealed how making students aware of their own reading strategies and helping them to adopt, control, revise and develop such strategies could lead to substantial improvement of $\mathrm{L} 2$ readers' reading ability.

In a more recent research, Dhieb-Henia (2003) examined the effect of explicit teaching of metacognitive strategies on declarative and procedural knowledge of students while reading English for specific purposes (ESP) research articles in an EFL context. Sixty-two undergraduate Tunisian students of Biology were divided into two groups - an experimental group and a control group. Both groups of students took pre-test and post-test readings, and 12 students participated in a retrospective protocol. Whereas the students in the experimental group received 
Vaez Dalili, M. \& Tavakoli, M.

explicit instruction on the rhetorical, discourse, and syntactic features of biology research articles as well as instruction on using metacognitive reading strategies, the students in the control group were exposed to the traditional approach to teaching ESP materials (i.e. reading, vocabulary, grammar). The purpose of the study was to explore whether the students in the experimental group would outperform the students in the control group. It was hypothesized that the explicit instruction of metacognitive strategies would result in the enhancement of both declarative and procedural knowledge of students. Based on the findings of the study obtained through the pre- and post-tests and the retrospective protocols, the explicit presentation of information on ESP research articles and the training of metacognitive strategies led to the development of the students' declarative/ procedural knowledge and also improved the reading proficiency of ESP students in EFL contexts.

\section{Method}

\subsection{Participants}

Two groups of college-level Iranian EFL students (35 in each group) participated in this study. The students were undergraduate freshmen who were admitted at University of Isfahan for full-time academic study, representing majors in engineering (i.e. mechanical engineering) and humanities (i.e. management) fields. Both groups were enrolled in ESP reading courses as required courses in their own fields. Identifying information elicited during the course of the study showed that the students in the two groups had similar characteristics in terms of age (engineering students mean age $=18.35$; humanities students mean age $=18.87$ ) and level of proficiency (i.e., lower-intermediate). The students' proficiency level was established on the basis of a placement test already administered to the students of each field of study to divide them into different proficiency levels.

\subsection{Data Collection}

\subsubsection{Instrument}

The data for this study were collected through the Metacognitive Awareness of Reading Strategies Inventory (MARSI). The MARSI instrument (Appendix A), used as a tool for assessing students' awareness and use of metacognitive reading strategies when reading academic materials, was first developed by Mokhtari (1998-2000) and later developed and validated in Mokhtari and Reichard (2002). It had been validated using a large student population $(n=825)$ with different reading abilities. The internal consistency reliability coefficient of the questionnaire (as determined by Cronbach's alpha) was reported to be 0.93 , which presumably shows a good degree of the reliability for the instrument. MARSI consists of three major categories of strategies: (i) Global Reading Strategies (GLOB), (ii) Problem-Solving Strategies (PROB), and (iii) Support Reading Strategies (SUP) (see Appendix B).

\subsubsection{Administration procedure}

The MARSI instrument was administered during regular class time with the help of the ESP instructors. Before completing the inventory, the students were given some explanations as to the purpose of the instrument, what the test included and how they should have completed the instrument. They were required to read each of the 30 items in MARSI and mark the number which best characterized the usage level for the strategies they used while reading ESP texts. Each item in the inventory was to be rated on a 5-point Likert-type scale ranging from 1 (I never or almost never do this) to 5 (I always or almost always do this). The students were required to complete the questionnaire within 15 minutes. The following list illustrates the steps used to administer the questionnaire:

$>$ Distribution of copies of the questionnaire to each student.

$>\quad$ Asking students to write identifying information (e.g., student name and age) in the given spaces.

$>\quad$ Reading the directions aloud. 
A comparative analysis of reading strategies across ESP students of humanities and engineering

$>\quad$ Making the students understand the procedure for rating each statement on the 5-point Likert scale.

$>$ Encouraging the students to say if they have any problems with any part of the inventory.

$>$ Asking the students to read the rubrics and the items and mark the appropriate number $1-5$ on the scale.

$>\quad$ Asking students to complete the questionnaire within 15 minutes.

3.2.3 Scoring procedure

The completed questionnaires were manually examined by the researchers, and, after discarding the incomplete ones, the 70 usable questionnaires (35 engineering and 35 humanities students) were coded for further interpretation and analysis. Following the guidelines given in the scoring rubric for the MARSI instrument (Appendix B), the scores obtained for the items of the inventory were transferred to the scoring sheet, which accompanied the questionnaire. Then, to calculate the total score, the scores in each column were added up. To obtain the overall average for the entire questionnaire as well as the average for each subscale of the inventory (i.e. Global Reading Strategies (GLOB), Problem-Solving Strategies (PROB), and Support Reading Strategies (SUP)), the total score was respectively divided by the number of all items $(\mathrm{n}=30)$ and the number of items in each subscale category (i.e. $n=13$ for GLOB, $n=8$ for PROB, and $n=9$ for SUP).

\subsubsection{Interpretation Procedure}

The interpretation of the students' scores required both descriptive and inferential statistical procedures. Regarding the descriptive interpretation of the students' overall scores as well as their scores in each category of strategies, Oxford's (1990) interpretation schemes were used. Based on this, the individual-level and group-level scores on the use of metacognitive strategies - ranging from 1 and 5 - fell into three levels: high (mean of 3.5 or higher), medium (mean of 2.5 to 3.4), and low (2.4 or lower) (Appendix B). Whereas the overall average showed how often an individual student used all the 30 metacognitive strategies, the averages for each category of metacognitive strategies (i.e. GLOB, PROB, and SUP) indicated the strategies employed most or least by each student.

As for inferential statistical procedures, thirty two-tailed independent-samples t-tests were run to examine whether significant differences existed between the two groups of ESP students with respect to each metacognitive reading strategy on the MARSI instrument. Also, another two-tailed independent-samples t-test was conducted to compare the overall means of strategy use across the two groups. The results of both descriptive and inferential statistical analyses are given in the following section.

\section{Results}

The results obtained are presented in Tables 2 and 3. Table 2 below contains data pertaining to the research question: Are there significant differences between engineering and humanities students in their metacognitive awareness and use of certain reading strategies while reading ESP materials? A two-tailed independent-samples t-test was conducted to compare the 30 means of strategy use across humanities and engineering students. The result of the $\mathrm{t}$-test showed that there was no significant difference between humanities $(\mathrm{M}=3.16, \mathrm{SD}=.50)$ and engineering students, $\mathrm{M}=3.39, \mathrm{SD}=.52 ; \mathrm{t}(68)=1.72, \mathrm{p}=.09$ (see Appendix $\mathrm{C}$ ). As seen in Table 2, all of the three categories of strategies (i.e. GLOB, PROB and SUP) as well as fifteen of the individual metacognitive strategies indicate significant differences between engineering and humanities students.

As Table 2 shows, for the students of humanities, the highest mean score $(X=3.91)$ and lowest mean score $(X=2.01)$ of strategy use respectively pertain to GLOB8 (i.e. using context clues) and SUP4 (i.e. discussing reading with others). For the students of engineering, the highest mean score $(\mathrm{X}=4.49)$ and lowest mean score $(X=2.46)$ of strategy use are respectively related to GLOB8 (i.e. using context clues) and SUP8 (i.e. going back 
Vaez Dalili, M. \& Tavakoli, M.

and forth in text). Whereas the mean score of the 'overall reading strategy' (ORS) is 3.16 for the students of humanities, it is 3.39 for engineering students.

Table 2

Detailed comparison of metacognitive reading strategies used by humanities and engineering students

\begin{tabular}{|c|c|c|c|c|c|c|c|}
\hline \multirow[t]{2}{*}{ Name } & \multirow[t]{2}{*}{ Strategy } & \multicolumn{2}{|c|}{$\begin{array}{c}\text { Humanities } \\
\text { Students }(n=35)\end{array}$} & \multicolumn{2}{|c|}{$\begin{array}{c}\text { Engineering } \\
\text { Students }(\mathrm{n}=35)\end{array}$} & \multirow[t]{2}{*}{$t(68)$} & \multirow[t]{2}{*}{$p$-value } \\
\hline & & Mean & $S D$ & Mean & $S D$ & & \\
\hline GLOB1 & Setting purpose for reading & 2.97 & 1.15 & 3.06 & 1.17 & 1.88 & 0.276 \\
\hline GLOB2 & Using prior knowledge & 3.55 & 1.03 & 3.62 & 1.09 & 3.89 & 0.329 \\
\hline GLOB3 & Previewing text before reading & 3.87 & 1.07 & 4.39 & 1.32 & 35.48 & $0.002 *$ \\
\hline GLOB4 & $\begin{array}{l}\text { Checking how text content fits } \\
\text { purpose }\end{array}$ & 2.84 & 1.18 & 2.88 & 1.24 & 5.77 & 0.081 \\
\hline GLOB5 & Skimming to note text characteristics & 3.85 & 1.29 & 4.12 & 0.87 & 26.07 & $0.000 *$ \\
\hline GLOB6 & Determining what to read & 3.21 & 0.99 & 3.49 & 1.18 & 33.74 & $0.001 *$ \\
\hline GLOB7 & Using text features (e.g., tables) & 3.15 & 1.30 & 3.35 & 1.55 & 0.63 & 0.612 \\
\hline GLOB8 & Using context clues & 3.91 & 1.09 & 4.49 & 0.93 & 19.44 & $0.001 *$ \\
\hline GLOB9 & $\begin{array}{l}\text { Using typographical aids (e.g., } \\
\text { italics) }\end{array}$ & 3.18 & 1.19 & 2.85 & 0.88 & 16.11 & $0.000^{*}$ \\
\hline GLOB10 & Critically evaluating what is read & 2.53 & 1.05 & 2.96 & 0.92 & 15.19 & $0.001 *$ \\
\hline GLOB11 & Resolving conflicting information & 2.67 & 0.91 & 2.84 & 1.01 & 4.65 & 0.189 \\
\hline GLOB12 & Predicting or guessing text meaning & 3.76 & 1.09 & 4.15 & 0.83 & 15.64 & $0.000 *$ \\
\hline GLOB13 & Confirming predictions & 3.55 & 1.28 & 3.61 & 1.17 & 5.43 & 0.511 \\
\hline PROB 1 & Reading slowly and carefully & 3.64 & 1.04 & 3.52 & 0.93 & 15.89 & $0.011 *$ \\
\hline PROB2 & Trying to stay focused on reading & 3.06 & 1.27 & 3.61 & 0.90 & 23.09 & $0.000 *$ \\
\hline PROB3 & Adjusting reading rate & 2.78 & 1.16 & 2.57 & 0.93 & 39.41 & $0.000^{*}$ \\
\hline PROB4 & Paying close attention to reading & 3.08 & 0.87 & 3.32 & 1.17 & 4.05 & 0.173 \\
\hline PROB5 & Pausing and thinking about reading & 2.92 & 0.91 & 3.11 & 1.25 & 7.16 & $0.007 *$ \\
\hline PROB6 & Visualizing information read & 2.96 & 1.03 & 3.06 & 0.94 & 2.79 & 0.321 \\
\hline PROB7 & Re-reading for better understanding & 3.03 & 0.96 & 3.68 & 1.11 & 3.28 & 0.097 \\
\hline PROB8 & $\begin{array}{l}\text { Guessing meaning of unknown } \\
\text { words }\end{array}$ & 3.87 & 0.93 & 4.06 & 1.01 & 26.78 & $0.000 *$ \\
\hline SUP1 & Taking notes while reading & 2.67 & 0.99 & 3.45 & 1.19 & 2.80 & 0.182 \\
\hline SUP2 & $\begin{array}{l}\text { Reading aloud when text becomes } \\
\text { hard }\end{array}$ & 3.74 & 1.17 & 3.50 & 0.99 & 30.07 & $0.000^{*}$ \\
\hline SUP3 & Summarizing text information & 3.14 & 0.83 & 3.53 & 1.09 & 27.46 & $0.004 *$ \\
\hline SUP4 & Discussing reading with others & 2.01 & 1.19 & 2.80 & 1.02 & 2.91 & 0.210 \\
\hline SUP5 & Underlining information in text & 3.32 & 1.22 & 3.31 & 1.27 & 2.33 & 0.513 \\
\hline SUP6 & Using reference materials & 2.13 & 0.97 & 2.84 & 0.95 & 2.09 & 0.235 \\
\hline SUP7 & $\begin{array}{l}\text { Paraphrasing for better } \\
\text { understanding }\end{array}$ & 2.81 & 1.14 & 3.90 & 0.88 & 1.09 & 0.096 \\
\hline SUP8 & Going back and forth in text & 3.71 & 1.02 & 2.46 & 1.32 & 26.84 & $0.000 *$ \\
\hline SUP9 & Asking oneself questions & 3.14 & 0.94 & 3.36 & 1.08 & 1.24 & 0.322 \\
\hline GLOB & Global Reading Strategies & 3.31 & 0.71 & 3.52 & 0.68 & 11.02 & $0.002 *$ \\
\hline PROB & Problem-Solving Strategies & 3.16 & 0.53 & 3.36 & 0.46 & 10.89 & $0.018 *$ \\
\hline SUP & Support Reading Strategies & 2.96 & 0.57 & 3.22 & 0.46 & 9.69 & $0.007 *$ \\
\hline ORS & Overall Reading Strategies & 3.16 & 0.67 & 3.39 & 0.62 & & \\
\hline
\end{tabular}

Note. ${ }^{*}$ shows significant difference between two groups on individual strategies (i.e. $\mathrm{p}<0.05$ )

The most and least frequently used metacognitive reading strategies reported by humanities and engineering students are listed in descending order in Table 3 in the following. The items at the top and bottom respectively show the most and least frequently used strategies respectively. For the humanities students, 10 of the 30 reading strategies $(33.33 \%)$ show high usage (i.e. mean of 3.5 or higher), whereas for the engineering students, 13 reading strategies $(43.33 \%)$ fall in the high usage range. Moreover, for the humanities students, 18 of the 30 reading strategies $(60 \%)$ fall in the medium usage range (i.e. 2.5 to 3.4 ), while for the engineering students 17 
A comparative analysis of reading strategies across ESP students of humanities and engineering

$(56.66 \%)$ reading strategies $(60 \%)$ are in the medium range of usage. Also, for the humanities students, $2(6.66 \%)$ of 30 reading strategies fall in the low usage range (i.e. 2.4 or lower), while for the engineering students, none of the strategies show low usage. Although there are commonalities between the two groups with respect to the use of the high usage and low usage strategies, there are a few differences, including 'going back and forth in text' (SUP8), 'paraphrasing for better understanding' (SUP7), 're-reading for better understanding' (PROB7), 'trying to stay focused on reading' (PROB2), 'summarizing text information' (SUP3), 'using reference materials' (SUP6), and 'discussing reading with others' (SUP4).

Table 3

The most and least frequently used reading strategies reported by humanities and engineering students

\begin{tabular}{|c|c|c|c|c|c|}
\hline \multicolumn{2}{|r|}{ Humanities Students $(n=35)$} & \multicolumn{4}{|c|}{ Engineering Students $(n=35)$} \\
\hline Name & Strategy & Mean & Name & Strategy & Mean \\
\hline GLOB8 & Using context clues & 3.91 & GLOB8 & Using context clues & 4.49 \\
\hline GLOB3 & Previewing text before reading & 3.87 & GLOB3 & Previewing text before reading & 4.39 \\
\hline PROB8 & Guessing meaning of unknown words & 3.87 & GLOB12 & Predicting or guessing text meaning & 4.15 \\
\hline GLOB5 & Skimming to note text characteristics & 3.85 & GLOB5 & Skimming to note text characteristics & 4.12 \\
\hline GLOB12 & Predicting or guessing text meaning & 3.76 & PROB8 & Guessing meaning of unknown words & 4.06 \\
\hline SUP2 & Reading aloud when text becomes hard & 3.74 & SUP7 & Paraphrasing for better understanding & 3.90 \\
\hline SUP8 & Going back and forth in text & 3.71 & PROB7 & Re-reading for better understanding & 3.68 \\
\hline PROB1 & Reading slowly and carefully & 3.64 & GLOB2 & Using prior knowledge & 3.62 \\
\hline GLOB2 & Using prior knowledge & 3.55 & GLOB13 & Confirming predictions & 3.61 \\
\hline \multirow[t]{4}{*}{ GLOB13 } & Confirming predictions & 3.55 & PROB2 & Trying to stay focused on reading & 3.61 \\
\hline & & & SUP3 & Summarizing text information & 3.53 \\
\hline & & & PROB1 & Reading slowly and carefully & 3.52 \\
\hline & & & SUP2 & Reading aloud when text becomes hard & 3.50 \\
\hline SUP5 & Underlining information in text & 3.32 & GLOB6 & Determining what to read & 3.49 \\
\hline GLOB6 & Determining what to read & 3.21 & SUP1 & Taking notes while reading & 3.45 \\
\hline GLOB9 & Using typographical aids (e.g., italics) & 3.18 & SUP9 & Asking oneself questions & 3.36 \\
\hline GLOB7 & Using text features (e.g., tables) & 3.15 & GLOB7 & Using text features (e.g., tables) & 3.35 \\
\hline SUP3 & Summarizing text information & 3.14 & PROB4 & Paying close attention to reading & 3.32 \\
\hline SUP9 & Asking oneself questions & 3.14 & SUP5 & Underlining information in text & 3.31 \\
\hline PROB4 & Paying close attention to reading & 3.08 & PROB5 & Pausing and thinking about reading & 3.11 \\
\hline PROB2 & Trying to stay focused on reading & 3.06 & GLOB1 & Setting purpose for reading & 3.06 \\
\hline PROB7 & Re-reading for better understanding & 3.03 & PROB6 & Visualizing information read & 3.06 \\
\hline GLOB1 & Setting purpose for reading & 2.97 & GLOB 10 & Critically evaluating what is read & 2.96 \\
\hline PROB6 & Visualizing information read & 2.96 & GLOB4 & Checking how text content fits purpose & 2.88 \\
\hline PROB5 & Pausing and thinking about reading & 2.92 & GLOB9 & Using typographical aids (e.g., italics) & 2.85 \\
\hline GLOB4 & Checking how text content fits purpose & 2.84 & GLOB11 & Resolving conflicting information & 2.84 \\
\hline SUP7 & Paraphrasing for better understanding & 2.81 & SUP6 & Using reference materials & 2.84 \\
\hline PROB3 & Adjusting reading rate & 2.78 & SUP4 & Discussing reading with others & 2.80 \\
\hline GLOB11 & Resolving conflicting information & 2.67 & PROB3 & Adjusting reading rate & 2.57 \\
\hline SUP1 & Taking notes while reading & 2.67 & SUP8 & Going back and forth in text & 2.46 \\
\hline GLOB 10 & Critically evaluating what is read & 2.53 & & & \\
\hline SUP6 & Using reference materials & 2.13 & & & \\
\hline SUP4 & Discussing reading with others & 2.01 & & & \\
\hline
\end{tabular}

\section{Conclusion and Discussion}

In this study, EFL students of humanities and engineering completed a 30-item questionnaire of metacognitive reading strategies while reading ESP materials. The data revealed two noteworthy findings. These findings, which are illustrated in graphic form in Figure 1 below, are summarized in the following.

In spite of the fact that the two groups of students were studying completely different fields of study, they reported strikingly similar patterns of reading strategy awareness and usage when reading college-level ESP materials in an EFL context. This is verified both through the t-test analysis - where no difference was found between the two groups - and the common hierarchy of the metacognitive strategies used by the students of engineering and humanities (i.e. GLOB $>$ PROB $>$ SUP). 
The engineering students reported using some types of reading strategies more frequently than did the humanities students, and this led to a relatively higher overall usage of reading strategies for the former group of students. Two significant differences in the use of reading strategies by the two groups of students are worth mentioning. First, some of the 30 metacognitive reading strategies seem to be used more frequently by the engineering students than the humanities students, including 'previewing text before reading' (GLOB3), 'using context clues' (GLOB8), 'predicting or guessing text meaning' (GLOB12), and 'trying to stay focused on reading' (PROB2). Second, some of the reading strategies appear to be more frequently used by the humanities students than the engineering students, including 'using typographical aids' (GLOB9), 'reading slowly and carefully' (PROB1), 'adjusting reading rate' (PROB3), 'reading aloud when text becomes hard' (SUP2), and 'going back and forth in text' (SUP8) (see Table 2).

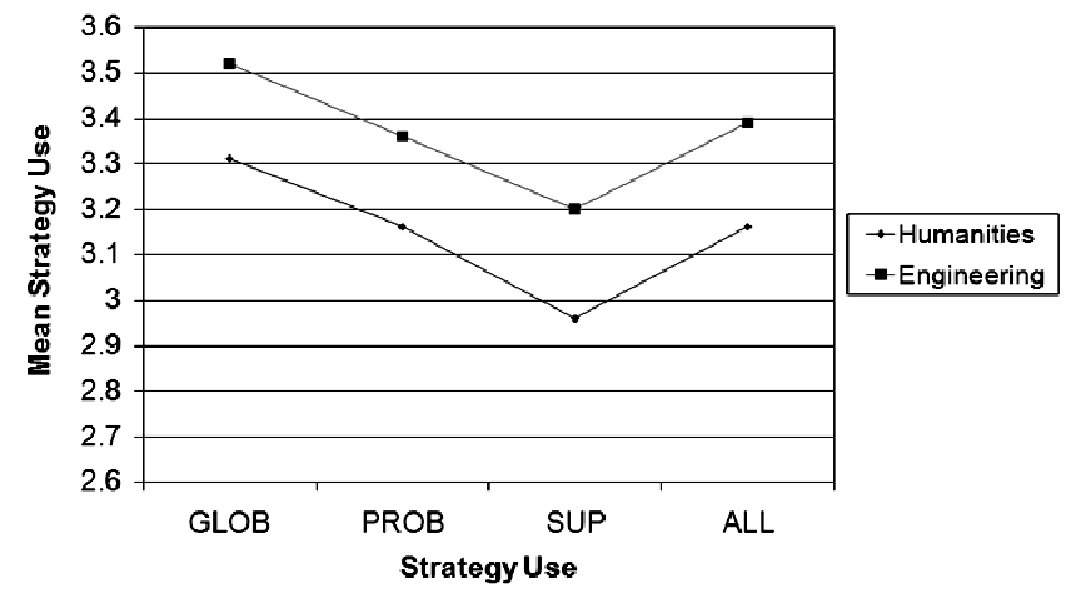

Figure 1. The mean of subscale (i.e. GLOB, PROB, and SUP) and overall reading strategy use by humanities and engineering students

The major findings of the study are significant in several respects. First, the collected data help reject the highly speculative assumption regarding the deficiencies in strategy-based ESP reading comprehension of the humanities students. As shown in Figure 1, not only the Global Reading Strategies (GLOB) and Support Reading Strategies (SUP), but also the Problem-Solving Strategies (PROB), which characterize skilled readers, are uniformly employed by the humanities and engineering students. So, the well-matched use of all of the three modules of MARSI across the humanities and engineering students pose challenges to the stereotype of the humanities students as 'disadvantaged' $\mathrm{L} 2$ readers.

Second, the findings of this study lend confirmation to the current belief that the humanities students need to be regarded as different L2 learners from the engineering students. Taking a look at Table 2, one can obviously see that the types of reading strategies used by the humanities students and engineering students actually differ in some considerable respects. However, such differences have unfortunately been considered as deficiencies of one group of students (i.e. the humanities students) and have not been taken as inherent requirements of the two different fields of study.

Third, although Figure 1 shows that the students of the group's report highly similar patterns of using the metacognitive reading strategies on MARSI, this can't let both researchers and practitioners overlook the difficulties the humanities students have in using certain types of strategies. Actually, there are certain problematic areas in strategy-based ESP reading of the humanities students, which deserve further scrutiny by both researchers and practitioners.

Owing to various constraints, the present study experienced certain limitations in terms of sampling, methodology and generalizability. As the first shortcoming, the present study, as with the bulk of research on the 
A comparative analysis of reading strategies across ESP students of humanities and engineering

reading strategies used by L2 readers (e.g. Knight, Padron, \& Waxman, 1985; Block, 1986; Carrell, 1989; Anderson, 1991; Auerbach \& Paxton, 1997), has dealt with young students at lower levels of proficiency. An additional constraint lies in the methodology of the studies, which stopped short of including protocol analysis based on verbal interviews or think-aloud procedures. Nevertheless, this was premised on the fact that less proficient L2 learners usually produce incomplete verbal reports than more skilled readers; hence the discrepancy between reported usage of metacognitive strategies versus actual usage of such strategies. A third limitation concerns the generalizability of the results of the study, which cannot be applied to other age groups (e.g. adolescents or middle aged L2 learners) or other fields of study (e.g. social sciences, applied sciences, medical sciences, etc.).

Granted that the present study emerged as but one research attempt, it follows that more rigorous endeavors are warranted if it is to be asserted with greater confidence that students with different fields of study similarly use metacognitive strategies while reading ESP materials. More research need to be conducted into the effect of such factors as age, students' gender, academic background, proficiency level, level of text difficulty, type of reading materials, and other relevant factors. Also, in order to better understand the metacognitive processes employed by the students while reading ESP texts, a close examination of the range of reading strategies can be carried out through protocol analysis (e.g. interviews and think-aloud procedures).

Some pedagogical implications are also extracted from the results of the study. EFL students of all fields of study should become aware of the importance of using metacognitive reading strategies while reading any kind of reading, including ESP readings. EFL instructors can help EFL students achieve this goal and help them become proficient ESP readers through the explicit instruction of the metacognitive reading strategies. Teaching students to become proficient L2 readers can be an optimal way for developing ESP reading skills, which will also lead to the enhancement of their academic achievement. Moreover, it is important for metacognitive reading strategies instruction to be integrated within the overall ESP reading curriculum so as to improve students' metacognition about reading. Furthermore, FLT practitioners as well as test makers can use the insights into ESP reading to facilitate their ESP instructions and to develop more reliable and valid ESP reading tests.

\section{References:}

Anderson, N. (1991). Individual differences in strategy use in second language reading and testing. Modern Language Journal, 75, 460-472. http://dx.doi.org/10.1111/j.1540-4781.1991.tb05384.x

Anderson, N. (1999). Exploring second language reading: Issues and strategies. Boston: Heinle and Heinle.

Auerbach, E. R., \& Paxton, D. (1997). "It's not the English thing": Bringing reading research into the ESL classroom. TESOL Quarterly, 31(2), 237-261. http://dx.doi.org/10.2307/3588046

Baker, L., \& Brown, A. L. (1984). Metacognitive skills in reading. In D. Pederson, Kamil, M., Barr, R., \& Mosenthal, P. (Eds.), Handbook of reading research (pp. 353-394). New York: Longman.

Barnett, M. A. (1988). Reading through context: How real and perceived strategy use affects L2 comprehension. Modern Language Journal, 72, 150-162. http://dx.doi.org/10.1111/j.1540-4781.1988.tb04177.x

Block, E. (1986). The comprehension strategies of second language readers. TESOL Quarterly, 20(3), 463-494. http://dx.doi.org/10.2307/3586295

Carrell, P. L. (1984). The effects of rhetorical organization on ESL readers. TESOL Quarterly, 18(3), 441-469. http://dx.doi.org/10.2307/3586714

Carrell, P. L. (1989). Metacognitive awareness and second language reading. Modern Language Journal, 73, 121-133. http://dx.doi.org/10.1111/j.1540-4781.1989.tb02534.x

Devine, J. (1988). A case of two readers: Models of reading and reading performance. In P. L. Carrell, Devine, J., Eskey, D. E. (Eds.), Interactive approaches to second language reading (pp. 127-139). Cambridge:

Cambridge University Press. http://dx.doi.org/10.1017/CBO9781139524513.015

Devine, J. (1993). The role of metacognition in second language reading and writing. In G. Joan \& Carson, L. I. (Eds.), Reading in the composition classroom: Second language perspective (pp. 105-130). Boston: Heinle \& Heinle. 
Vaez Dalili, M. \& Tavakoli, M.

Dhieb-Henia, N. (2003). Evaluating the effectiveness of metacognitive strategy training for reading research articles in an ESP context. English for Specific Purposes, 22, 387-417. http://dx.doi.org/10.1016/S0889-4906(03)00017-6

Færch, C., \& Kasper, G. (1983). Strategies in interlanguage communication. New York: Longman.

Flavell, J. H. (1981). Cognitive monitoring. In W. P. Dickson (Ed.), Children's oral communication skills (pp. 35-60). New York: Academic Press.

Grabe, W., \& Stoller, F. L. (2002). Teaching and researching reading. New York: Longman.

Knight, S., Padron, Y., Waxman, H., 1985. The cognitive reading strategies of ESL students. TESOL Quarterly, 19(4), 789-792. http://dx.doi.org/10.2307/3586677

Mokhtari, K. (1998-2000). Metacognitive-awareness-of-reading-strategies inventory (MARSI). Unpublished instrument, Oklahoma State University, Stillwater, Oklahoma, USA.

Mokhtari, K., \& Reichard, C. A. (2002). Assessing students' metacognitive awareness of reading strategies. Journal of Educational Psychology, 94(2), 249-259. http://dx.doi.org/10.1037/0022-0663.94.2.249

O’Malley, J. M., \& Chamot, A. U. (1990). Learning strategies in second language acquisition. Cambridge: Cambridge University Press. http://dx.doi.org/10.1017/CBO9781139524490

Oxford, R. (1990). Language learning strategies. New York: Newbury House.

Paris, S. G., \& Jacobs, J. E. (1984). The benefits of informed instruction for children's reading awareness and comprehension skills. Child Development, 55, 2083-2093. http://dx.doi.org/10.2307/1129781

Pressley, M. (2000). What should comprehension instruction be the instruction of? In M. L. Kamil, Mosenthal, P. B., Pearson, P. D., \& Barr, R. (Eds.), Handbook of reading research (Vol. III) (pp. 545-561). Mahwah, NJ: Lawrence Erlbaum Associates.

Sarig, G. (1993). Composing a study-summary: A reading/writing encounter. In G. Joan \& Carson, L. I. (Eds.), Reading in the composition classroom: Second language perspective (pp. 161-182). Boston: Heinle \& Heinle.

Wenden, A., \& Rubin, J. (1987). Learning strategies in language learning. New York: Prentice-Hall International. 
A comparative analysis of reading strategies across ESP students of humanities and engineering

Appendices

Appendix A

Metacognitive Awareness of Reading Strategies Inventory (Mokhtari \& Reichard, 2002)

Student name:

Age:

Date:

Directions: Listed below are statements about what people do when they read academic or school-related materials such as textbooks or library books.

Five numbers follow each statement $(1,2,3,4,5)$, and each number means the following:

- 1 means "I never or almost never do this."

- 2 means "I do this only occasionally."

- 3 means "I sometimes do this" (about $\mathbf{5 0 \%}$ of the time).

- 4 means "I usually do this."

- 5 means "I always or almost always do this."

After reading each statement, circle the number $(1,2,3,4$, or 5$)$ that applies to you using the scale provided. Please note that there are no right or wrong answers to the statements in this inventory.

\begin{tabular}{|c|c|c|c|c|c|c|}
\hline \multirow{2}{*}{$\begin{array}{l}\text { Type } \\
\text { GLOB }\end{array}$} & \multirow{2}{*}{$\begin{array}{ll}\text { Strategy } \\
1 . \text { I have a purpose in mind when I read. }\end{array}$} & \multicolumn{5}{|c|}{ Scale } \\
\hline & & 1 & 2 & 3 & 4 & 5 \\
\hline SUP & 2. I take notes while reading to help me understand what I read. & 1 & 2 & 3 & 4 & 5 \\
\hline GLOB & 3. I think about what I know to help me understand what I read. & 1 & 2 & 3 & 4 & 5 \\
\hline GLOB & 4. I preview the text to see what it's about before reading it. & 1 & 2 & 3 & 4 & 5 \\
\hline SUP & 5. When text becomes difficult, I read aloud to help me understand what I read. & 1 & 2 & 3 & 4 & 5 \\
\hline SUP & 6. I summarize what I read to reflect on important information in the text. & 1 & 2 & 3 & 4 & 5 \\
\hline GLOB & 7. I think about whether the content of the text fits my reading purpose. & 1 & 2 & 3 & 4 & 5 \\
\hline PROB & 8. I read slowly but carefully to be sure I understand what I'm reading. & 1 & 2 & 3 & 4 & 5 \\
\hline SUP & 9. I discuss what I read with others to check my understanding. & 1 & 2 & 3 & 4 & 5 \\
\hline GLOB & 10. I skim the text first by noting characteristics like length and organization. & 1 & 2 & 3 & 4 & 5 \\
\hline PROB & 11. I try to get back on track when I lose concentration. & 1 & 2 & 3 & 4 & 5 \\
\hline SUP & 12. I underline or circle information in the text to help me remember it. & 1 & 2 & 3 & 4 & 5 \\
\hline PROB & 13. I adjust my reading speed according to what I'm reading. & 1 & 2 & 3 & 4 & 5 \\
\hline GLOB & 14. I decide what to read closely and what to ignore. & 1 & 2 & 3 & 4 & 5 \\
\hline SUP & 15. I use reference materials such as dictionaries to help me understand what I read. & 1 & 2 & 3 & 4 & 5 \\
\hline PROB & 16. When text becomes difficult, I pay closer attention to what I'm reading. & 1 & 2 & 3 & 4 & 5 \\
\hline GLOB & 17. I use tables, figures, and pictures in text to increase my understanding. & 1 & 2 & 3 & 4 & 5 \\
\hline PROB & 18. I stop from time to time and think about what I'm reading. & 1 & 2 & 3 & 4 & 5 \\
\hline GLOB & 19. I use context clues to help me better understand what I'm reading. & 1 & 2 & 3 & 4 & 5 \\
\hline SUP & 20. I paraphrase (restate ideas in my own words) to better understand what I read. & 1 & 2 & 3 & 4 & 5 \\
\hline PROB & 21. I try to picture or visualize information to help remember what I read. & 1 & 2 & 3 & 4 & 5 \\
\hline GLOB & 22. I use typographical aids like boldface and italics to identify key information. & 1 & 2 & 3 & 4 & 5 \\
\hline GLOB & 23. I critically analyze and evaluate the information presented in the text. & 1 & 2 & 3 & 4 & 5 \\
\hline SUP & 24. I go back and forth in the text to find relationships among ideas in it. & 1 & 2 & 3 & 4 & 5 \\
\hline GLOB & 25. I check my understanding when I come across conflicting information. & 1 & 2 & 3 & 4 & 5 \\
\hline GLOB & 26. I try to guess what the material is about when I read. & 1 & 2 & 3 & 4 & 5 \\
\hline PROB & 27. When text becomes difficult, I reread to increase my understanding. & 1 & 2 & 3 & 4 & 5 \\
\hline SUP & 28. I ask myself questions I like to have answered in the text. & 1 & 2 & 3 & 4 & 5 \\
\hline GLOB & 29. I check to see if my guesses about the text are right or wrong. & 1 & 2 & 3 & 4 & 5 \\
\hline PROB & 30. I try to guess the meaning of unknown words or phrases. & 1 & 2 & 3 & 4 & 5 \\
\hline
\end{tabular}


Appendix B

Scoring rubric for MARSI instrument

Student name:

Age:

Date:

1. Write your response to each statement (i.e., 1, 2, 3, 4, or 5) in each of the blanks.

2. Add up the scores under each column. Place the result on the line under each column.

3. Divide the subscale score by the number of statements in each column to get the average for each subscale.

4. Calculate the average for the whole inventory by adding up the subscale scores and dividing by 30 .

5. Compare your results to those shown below.

6. Discuss your results with your teacher or tutor.

\section{Global Reading \\ Strategies \\ (GLOB subscale)}

1.

3.

4.

7.

10.

14

17.

19

22.

23

25 .

26.

29.

GLOB score

GLOB mean

\section{Problem-Solving \\ Strategies \\ (PROB subscale)}

8.

11.

13.

16.

18.

21.

27.

30.

\section{Support Reading \\ Strategies \\ (SUP subscale)}

2.

5.

6.

9.

12.

15.

20.

24.

28 .

\section{Overall Reading \\ Strategies}

\section{GLOB \\ PROB \\ SUP}

PROB score PROB mean
SUP score SUP mean
Overall score Overall mean

Key to averages: 3.5 or higher _ high 2.5-3.4 _ medium 2.4 or lower _ low

\section{Interpreting your scores:}

The overall average indicates how often you use reading strategies when reading academic materials. The average for each subscale of the inventory shows which group of strategies (i.e., global, problem solving, and support strategies) you use most when reading. With this information, you can tell if you score very high or very low in any of these strategy groups. Note, however, that the best possible use of these strategies depends on your reading ability in English, the type of material read, and your purpose for reading it. A low score on any of the subscales or parts of the inventory indicates that there may be some strategies in these parts that you might want to learn about and consider using when reading. 
Categories of reading strategies measured by the Metacognitive Awareness of Reading Strategies Inventory (MARSI)

\section{Global Reading Strategies (GLOB)}

Examples include setting purpose for reading, activating prior knowledge, checking whether text content fits purpose, predicting what text is about, confirming predictions, previewing text for content, skimming to note text characteristics, making decisions in relation to what to read closely, using context clues, using text structure, and using other textual features to enhance reading comprehension. (Items 1, 3, 4, 7, 10, 14, 17, 19, 22, 23, 25, 26, 29)

\section{Problem-Solving Strategies (PROB)}

Examples include reading slowly and carefully, adjusting reading rate, paying close attention to reading, pausing to reflect on reading, rereading, visualizing information read, reading text out loud, and guessing meaning of unknown words. (Items $8,11,13,16,18,21,27,30$ )

\section{Support Reading Strategies (SUP)}

Examples include taking notes while reading, paraphrasing text information, revisiting previously read information, asking self questions, using reference materials as aids, underlining text information, discussing reading with others, and writing summaries of reading. (Items 2, 5, 6, 9, 12, 15, 20, 24, 28) 
Vaez Dalili, M. \& Tavakoli, M.

\section{Appendix C}

Two-tailed independent samples t-test showing no significant difference in the overall average of the metacognitive strategy use across humanities and engineering students

\section{Group Statistics}

\begin{tabular}{|c|c|c|c|c|c|}
\hline & & & & Std. & Std. Error \\
\hline & Group & $\mathrm{N}$ & Mean & Deviation & Mean \\
\hline \multirow[t]{2}{*}{ Major } & Humanities & 30 & 3.1683 & .50530 & .09225 \\
\hline & Engineering & 30 & 3.3963 & .52065 & .09506 \\
\hline
\end{tabular}

Independent Samples Test

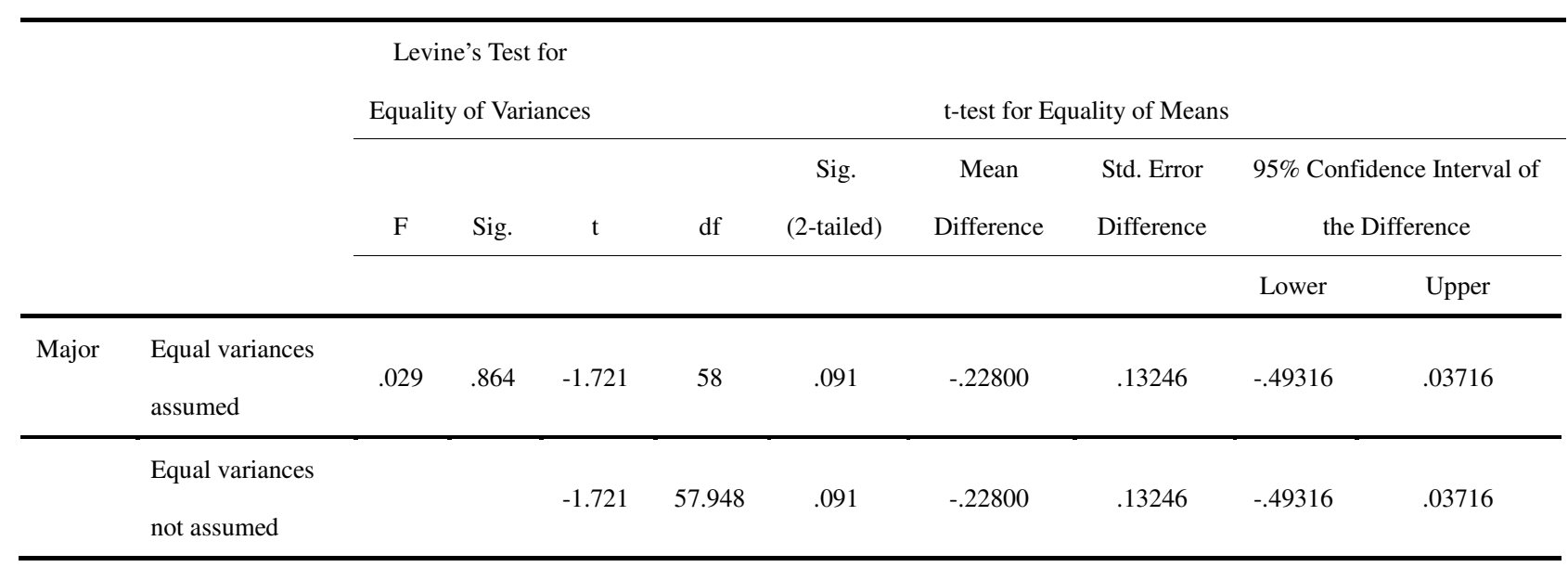

